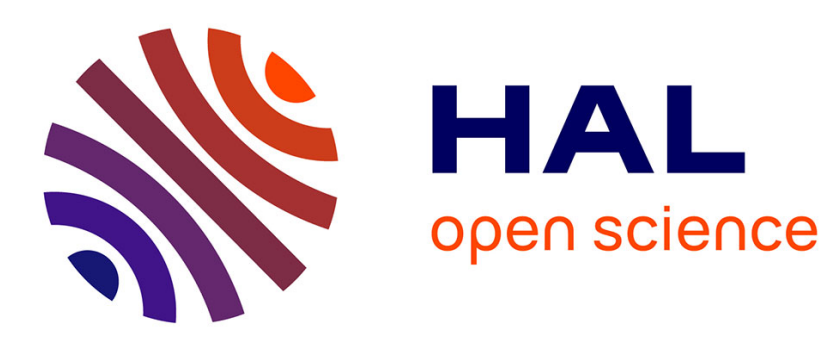

\title{
Time resolved studies on pulsed fluorocarbon plasmas using chirped quantum cascade lasers
}

\author{
S Welzel, S Stepanov, J Meichsner, J Röpcke
}

\section{To cite this version:}

S Welzel, S Stepanov, J Meichsner, J Röpcke. Time resolved studies on pulsed fluorocarbon plasmas using chirped quantum cascade lasers. Journal of Physics D: Applied Physics, 2010, 43 (12), pp.124014. 10.1088/0022-3727/43/12/124014 . hal-00569561

\section{HAL Id: hal-00569561 https://hal.science/hal-00569561}

Submitted on 25 Feb 2011

HAL is a multi-disciplinary open access archive for the deposit and dissemination of scientific research documents, whether they are published or not. The documents may come from teaching and research institutions in France or abroad, or from public or private research centers.
L'archive ouverte pluridisciplinaire HAL, est destinée au dépôt et à la diffusion de documents scientifiques de niveau recherche, publiés ou non, émanant des établissements d'enseignement et de recherche français ou étrangers, des laboratoires publics ou privés. 


\title{
Time resolved studies on pulsed fluorocarbon plasmas using chirped quantum cascade lasers
}

\author{
S Welzel ${ }^{1,3}$, S Stepanov ${ }^{2}$, J Meichsner ${ }^{2}$ and J Röpcke ${ }^{1}$ \\ ${ }^{1}$ Leibniz Institute for Plasma Science and Technology, Felix-Hausdorff-Str. 2, 17489 \\ Greifswald, Germany \\ ${ }^{2}$ Institute of Physics, Ernst-Moritz-Arndt University, Felix-Hausdorff-Str. 6, 17489 \\ Greifswald, Germany \\ Email:welzel@physik.uni-greifswald.de \\ ${ }^{3}$ Present address: Department of Applied Physics, Eindhoven University of \\ Technology, P.O. Box 513, 5600 MB Eindhoven, The Netherlands
}

\begin{abstract}
The kinetics of stable species has been studied in-situ in pulsed $\mathrm{CF}_{4} / \mathrm{H}_{2}$ radio frequency discharges by means of time resolved quantum cascade laser absorption spectroscopy. The absorption spectra were usually recorded with a time resolution of $5 \mathrm{~ms}$ and required a multi-species analysis, because of interfering complex absorption features of $\mathrm{CF}_{4}$ and $\mathrm{C}_{3} \mathrm{~F}_{8}$. For this reason, measurements were carried out at two different spectral positions. High resolution spectroscopic data were established by calibrating effective absorption cross sections and their relative temperature dependences for the relevant low pressure conditions $(10 \mathrm{~Pa})$. During the discharge a decrease of the $\mathrm{CF}_{4}$ density by $\sim 12 \%$ was observed. The off-phase was mainly characterised by the gas exchange. The $\mathrm{C}_{3} \mathrm{~F}_{8}$ density in the off-phase was found to be of the order of the detection limit $\left(3 \times 10^{13} \mathrm{~cm}^{-3}\right)$. Spectra acquired during the plasma-on phase showed a rapid temperature-induced increase of the absorption signal and, additionally, suggested the influence of a short-lived broadband absorbing species. The reasonable assumption of the presence of $\mathrm{CF}_{4}$ hotbands, has not yet enabled a further quantification.
\end{abstract}

Short Title: Time resolved QCLAS studies of fluorocarbon plasmas

PACS numbers: 07.57.Ty, 42.62.Fi, 52.70.Kz, 52.80.Pi

Submitted to: Journal of Physics D: Applied Physics 


\section{Introduction}

Fluorocarbon plasmas are applied in industry and fundamental research for etching or deposition purposes and as model systems. Pulsing of the discharge provides an additional means of tuning plasma parameters, e.g., densities and temperatures, which become time dependent [1,2]. However, a better understanding of the plasma chemistry and kinetics in these complex discharges is still required. Thus time resolved information on absolute number densities of transient and stable species is desirable.

Several plasma diagnostic methods have been used so far to measure densities of radicals or other neutral species in fluorocarbon containing plasmas [3], among them optical emission spectroscopy [4,5], mass spectrometry [5,6], laser induced fluorescence [6-8] or absorption spectroscopy (AS) in the ultraviolet $[6,9,10]$ or infrared (IR) spectral range. Apart from Fourier transform (FT-) IR studies $[11,12]$, tuneable diode laser absorption spectroscopy (TDLAS) has been established as a suitable diagnostic tool for monitoring absolute ground state number densities in plasmas. For years tuneable lead salt diode lasers have been used as mid-IR light sources emitting between 3 and $20 \mu \mathrm{m}$, where characteristic absorption lines of many molecular species are normally located [13,14]. Specifically, IR-TDLAS has been applied for time resolved studies of $\mathrm{CF}$ or $\mathrm{CF}_{2}$ radicals and $\mathrm{C}_{2} \mathrm{~F}_{4}$ as a stable reaction product in capacitively coupled radio frequency ( $\mathrm{rf}$ ) $\mathrm{CF}_{4} / \mathrm{H}_{2}$ pulsed plasmas $(13.56 \mathrm{MHz})$ [1]. Furthermore, based on the simultaneous monitoring of three selected absorption lines, the time dependence of the rotational temperature of the $\mathrm{CF}_{2}$ radical was determined within a plasma pulse [2]. Recently, quantum cascade lasers (QCL) have become available as alternative light sources in the midIR spectral range $(3-20 \mu \mathrm{m})$ [15]. After their first spectroscopic application [16] pulsed QCLs have rapidly been employed for chemical sensing in general and for plasma diagnostics and plasma process monitoring in particular [17-22]. Different modes can be used to tune the single mode emission of a distributed feedback QCL over the spectral transitions of interest. Particularly the intra pulse mode is of high interest for time resolved measurements. For this tuning approach a relatively long laser pulse is used. The internal heating of the QCL causes a frequency down-chirped laser pulse which can be used to acquire a sweep of about $1 \mathrm{~cm}^{-1}$ within the pulse width of typically a few hundred nanoseconds [23]. The time resolution is thus theoretically limited by the pulse length of the laser. While IRTDLAS generally provides an adequate means for measurements in reactive plasmas, QCLAS may now facilitate an even better time resolution.

However, absorption features measured under low pressure conditions by using pulsed QCLs are typically affected by obstacles, i.e. the rapid passage effect which may be accompanied by potential power saturation of the transitions [24,25]. Accurate quantitative results can be obtained if a careful calibration [18,19] or normalisation [20] is performed. This approach is also suitable for complex molecular spectra where high resolution spectroscopic data are absent or have to be extracted from additional jet cooled experiments. In this case, an effective absorption cross section defined and calibrated for a specific spectral micro-window is also sufficient. Stancu et al. demonstrated this for $\mathrm{SiF}_{4}$ where no temperature dependence was observed, since contributions from several spectral lines compensated each other [18].

This article concerns pulsed $\mathrm{CF}_{4} / \mathrm{H}_{2}$ capacitively coupled rf discharges and focuses on the time resolved determination of the absolute concentrations of stable molecules. A pulsed QCL emitting at $7.86 \mu \mathrm{m}\left(1269-1275 \mathrm{~cm}^{-1}\right)$ was used for measurements of complex absorption features of $\mathrm{CF}_{4}$ and $\mathrm{C}_{3} \mathrm{~F}_{8}$ [11,26-28]. For $\mathrm{C}_{3} \mathrm{~F}_{8}$ only coarse spectra or band integrated absorption cross sections are available in literature. For $\mathrm{CF}_{4}$ a few high resolution IR-TDLAS measurements around the band origin at $1283 \mathrm{~cm}^{-1}$ are reported, but these studies provide only line positions [29,30] or relative absorption cross sections [31]. Absolute absorption cross sections for $\mathrm{CF}_{4}$ provided by the HITRAN database (2004 edition, [32]) have usually been acquired at several hundreds of Torr and hence are limited in their spectral resolution. For this reason, effective absorption cross sections had to be deduced for $\mathrm{CF}_{4}$ and $\mathrm{C}_{3} \mathrm{~F}_{8}$ by a complementary calibration. This approach simultaneously factors in the non-linear absorption effects caused by the pulsed QCL. Additionally, the temperature dependence of the absorption cross sections was studied.

The paper is organized as follows: section 2 describes the experimental arrangement and section 3 follows with spectroscopic issues, i.e. the calibration procedure and the discrimination of multiple species in the spectra. The results of measurements in pulsed rf discharges are discussed in respect of the temperature increase in section 4. 


\section{Experimental setup}

The experimental arrangement, which is schematically shown in figure 1, consists of two main parts: the discharge setup and the optical arrangement. The discharge setup has been described in detail elsewhere $[1,2,33]$ and is therefore only briefly considered here. The asymmetrical, capacitively coupled rf discharge $(13.56 \mathrm{MHz})$ was created in a cylindrical stainless steel vacuum chamber. A rf generator provided $100 \mathrm{~W}$ to the powered electrode. A master pulse generator (MPG) was used to pulse the discharge with a period of $3 \mathrm{~s}$ and a duty cycle of $1 / 3$ (i.e. $1 \mathrm{~s}$ on and $2 \mathrm{~s}$ off). The gas mixture was made of $\mathrm{CF}_{4}$ and $\mathrm{H}_{2}$ with a constant gas flow of 7 and $3 \mathrm{sccm}$ respectively. The total gas pressure was kept constant at about $10 \mathrm{~Pa}$.

Additionally, the MPG served to synchronize the emission of the pulsed QCL (figure 2). The MPG provided a master gate TTL trigger which primarily determined the plasma on-phase (figure 2a). Next, a delay generator launched a sequence of trigger pulses for the QCL with a delay time of $t_{\text {del }}$ after the rising edge of the MPG signal (figure $2 \mathrm{~b}$ and 2c). The burst of subsequent QCL trigger events was realized by a frequency generator. The repetition frequency of the trigger events defined the time resolution of the measurements $t_{\text {res }}$ (figure $2 \mathrm{~d}$ ). Typically, a burst of 600 pulses with a time resolution of $t_{\text {res }}=5 \mathrm{~ms}$, launched at $t_{\mathrm{del}}=500 \mathrm{~ns}$, was used to map the entire plasma pulse. In other words, using this time resolution the recovery time of the QCL after its emission was long enough to record spectra from the entire discharge pulse by means of a single burst of trigger pulses. Finally, to increase the signal to noise ratio, 25 of such sequences (i.e. from 25 subsequent plasma cycles) were recorded and averaged yielding 600 individual averaged spectra. All calibration data have been recorded under identical trigger conditions as for the plasma measurements. This approach was required, since changes in the trigger frequency (e.g., to speed up the data acquisition) would affect the heat sink temperature and thus the output frequency of the QCL.

The QCL radiation was collected by an off-axis parabolic mirror (OAP) (50 mm diameter, f/0.99) and guided through the plasma reactor in a double pass configuration $(\sim 90 \mathrm{~cm})$, approximately $4 \mathrm{~cm}$ above the rf electrode. Beam shaping optics (BO, e.g. telescopes) collimated and reduced the diameter of the IR beam to match the shared $\sim 30 \mathrm{~mm}$ entrance and exit port of the reactor (figure 1). Further details can be found elsewhere [34]. A fast thermoelectrically (TE) cooled detector $\left(\mathrm{D}_{2}\right.$, neoplas control, VIGO element PDI 3TE-10/12) was placed close to the plasma chamber where the transmitted light was collected by an OAP (25.4 mm diameter, f/0.64). A small fraction of the QCL output power was deflected by a ZnSe beam splitter (BS) into a reference path, where a second fast TE cooled detector $\left(D_{1}\right)$ was placed for triggering purposes. The rising edge of the QCL signal provided a stable trigger for the digitizing oscilloscope (LeCroy, WR104Xi) and obviates uncertainties due to jitter effects. Reliable triggering is essential because a single absorption line spreads usually over less than $5 \mathrm{~ns}$ while the typical jitter between the trigger of the QCL power supply and the laser emission is about $1 \mathrm{~ns}$. The pulsed room temperature QCL (Alpes Lasers) emitting between 1269 and $1275 \mathrm{~cm}^{-1}$ was operated with a QCL measurement and control system (Q-MACS, neoplas control) in a water cooled laser housing. All measurements were carried out in the intra pulse mode with a laser pulse width of $300 \mathrm{~ns}$, i.e. a spectral coverage of $\sim 1 \mathrm{~cm}^{-1}$.

\section{Spectroscopic issues}

Figure 3 illustrates the spectral range used in this study. For measurements of the target species in the discharge reduced interferences from other plasma produced transient or stable fluorocarbons were required. The upper panel of figure 3 shows normalized FT-IR spectra for three stable $\mathrm{C}_{\mathrm{x}} \mathrm{F}_{\mathrm{y}}$ molecules between 1269 and $1275 \mathrm{~cm}^{-1}$. The selected spectral range is shifted from the maximum of the $\mathrm{CF}_{4}$ absorption band at $1283 \mathrm{~cm}^{-1}$. Under the present experimental conditions the strong $\mathrm{CF}_{4}$ absorption signal around the band origin would have led to an almost total attenuation of the incident radiation. Thus, a part of the P-branch with weaker absorption features was used. No other stable molecules than $\mathrm{C}_{3} \mathrm{~F}_{8}$ may interfere with $\mathrm{CF}_{4}$ absorption features in the considered range. Potential contributions of $\mathrm{CF}_{3}$ and CF radicals (figure 3, lower panel) are negligible due to their weak absorption features or low concentrations.

Highly resolved QCLAS spectra of pure $\mathrm{CF}_{4}$ and $\mathrm{C}_{3} \mathrm{~F}_{8}$ measured in the discharge vessel (without 
plasma) are displayed in the lower panel of figure 4. The spectral range was successively mapped by tuning the heat sink temperature of the QCL while keeping pulse width and repetition frequency constant. Absorption features of $\mathrm{C}_{2} \mathrm{~F}_{6}$ could not be detected for pressures up to several tens of $\mathrm{Pa}$. Notably, the $\mathrm{CF}_{4}$ absorbance in figure 4 exhibits significant fluctuations, which are caused by the rapid passage features of spectrally resolved $\mathrm{CF}_{4}$ absorption lines. This effect is smoothed in the case of the dense $\mathrm{C}_{3} \mathrm{~F}_{8}$ spectrum.

In order to discriminate the contributions of both $\mathrm{CF}_{4}$ and $\mathrm{C}_{3} \mathrm{~F}_{8}$, all plasma measurements were performed within two spectral micro-windows $\left(\mathrm{R}_{1}, \mathrm{R}_{2}\right)$ centred around $1271 \mathrm{~cm}^{-1}$ and $1274 \mathrm{~cm}^{-1}$ where the ratio of the absorption cross sections is considerably different (figure 4 , lower panel). Both microwindows were also used to quantify the effective absorption cross sections $\sigma^{\text {eff }}$ for $\mathrm{CF}_{4}$ and $\mathrm{C}_{3} \mathrm{~F}_{8}$.

Following Beer-Lambert law, the number density $n$ of an absorbing species is determined from the ratio of the incident and transmitted intensity $I_{0}$ and $I$ along the line of sight of length $L$

$$
\ln \left(I_{0}(v) / I(v)\right)=n \sigma(v) L
$$

where $\sigma(v)$ is the absorption cross section. For a single, isolated absorption feature the integrated absorption coefficient (or line strength) is often used. However, in the case of dense or complex spectra (e.g., $\mathrm{CF}_{4}$ or $\mathrm{C}_{3} \mathrm{~F}_{8}$ ) this is not applicable. As pointed out earlier, literature values with the required spectral resolution were absent and non-linear absorption effects caused by the pulsed QCL had to be considered. Therefore, effective absorption cross sections $\sigma^{\text {eff }}$ of $\mathrm{CF}_{4}$ and $\mathrm{C}_{3} \mathrm{~F}_{8}$ have been extracted for $\mathrm{R}_{1}$ and $\mathrm{R}_{2}$ by analysing corresponding calibration spectra.

As discussed in section 2, even a small inevitable jitter of less than $1 \mathrm{~ns}$ in the trigger may cause a nonnegligible error, since not the peak but the wing of an absorption feature would be analysed at a constant temporal position in the spectrum. This error can sufficiently be reduced, if a carefully defined spectral range $\Delta v$ is used which yields

$$
\sigma^{\text {eff }}(\langle v\rangle)=\frac{1}{n L} \ln \left(\frac{I_{0}(\langle v\rangle)}{I(\langle v\rangle)}\right)=\frac{1}{n L} \ln \left(\frac{\left\langle I_{0}(v)\right\rangle \cdot \Delta v}{\langle I(v)\rangle \cdot \Delta v}\right)=\frac{1}{n L} \ln \left(\frac{A_{0}}{A}\right) .
$$

Instead of calculating the absorbance from the transmitted intensities $I$ at $v$ the area (or integral) $A \approx I \Delta v$ can be employed in predefined ranges. The value of $\Delta v$ cancels out in equation (2). The effective absorption cross sections for $\mathrm{CF}_{4}$ and $\mathrm{C}_{3} \mathrm{~F}_{8}$ obtained at room temperature by this approach are plotted in figure 4 (upper panel) for 10 and $25 \mathrm{~Pa}$. In practice, each spectral micro-window $\left(\mathrm{R}_{1}\right.$ and $\left.\mathrm{R}_{2}\right)$ corresponds to a $300 \mathrm{~ns}$ chirped QCL pulse for which 3 areas $A_{\mathrm{i}}$ of different $\Delta v$ have been selected. As could be expected, the most extended area covering the entire laser pulse represents an average for the corresponding spectral micro-window resulting in a $\sigma^{\text {eff }}$ which is found to be between those obtained from the smaller areas $A_{i}$.

The calibration measurements shown in figure 4 were carried out under flowing gas conditions in the plasma chamber to obviate any change of the gas mixture, e.g., due to gas decomposition, which might be present in a closed volume of a reference cell. This approach also enables the parameters, such as gas pressure, absorption signal etc., to be adapted to the experimental conditions as close as possible. On the other hand a homogeneous external heating of the gas phase in the reactor volume was not feasible to study the temperature dependence $\sigma^{\text {eff }}(T)$. Thus, only in this case, a metallic reference cell was placed in the beam path and externally heated up to $400 \mathrm{~K}$ by a heating tape.

All absorption cross sections should be considered as averaged values with a total error of about $15 \%$. This includes uncertainties in the pressure and gas flow measurements as well as in the data acquisition from the detector, e.g., baseline stability over time.

The $\sigma^{\text {eff }}$ values deduced at $25 \mathrm{~Pa}$ reveal a systematic difference compared to those at $10 \mathrm{~Pa}$. Power saturation effects caused by the QCL may explain the reduced absorption cross sections at $25 \mathrm{~Pa}$ since the relaxation times in the low pressure regime are insufficient to cancel this effect. It should be noted, that power saturation is present for all pressures or number densities, but it is more apparent at higher values and hence underlines the relevance of performing a calibration close to the experimental conditions. 
In figure 5 the calibrated effective absorption cross sections of $\mathrm{CF}_{4}$ are compared with data provided by the HITRAN database [32]. The HITRAN data were measured at temperatures below $300 \mathrm{~K}$ and at pressures considerably higher than those used here (at least 90 times higher). The recently acquired data are in good agreement with other non-highly resolved literature values $[37,38]$ though non-linear effects were present during the calibration procedure.

It can be also seen in figure 5 that the $\mathrm{CF}_{4}$ absorption cross section increases by $\sim 25 \%$ from $273 \mathrm{~K}$ to $296 \mathrm{~K}$ (solid black and grey traces). Consequently, $\sigma^{\text {eff }}(T)$ has to be considered for plasma diagnostic measurements where elevated gas temperatures are usually observed. The temperature dependence $\sigma^{\text {eff }}(T>296 \mathrm{~K})$ for both spectral micro-windows has been established elsewhere [34]. The relative changes of $\sigma^{\text {eff }}(T)$ observed for $\mathrm{CF}_{4}$ and $\mathrm{C}_{3} \mathrm{~F}_{8}$ respectively were parameterized by second order polynomials in order to apply $\sigma^{\text {eff }}(T)$ during the multi-species analysis of the spectra acquired in the plasma.

\section{Results and discussion}

Since the spectral features of $\mathrm{CF}_{4}$ and $\mathrm{C}_{3} \mathrm{~F}_{8}$ (further denoted with index $k=1$ and 2, respectively) interfere in the target spectral range, the number densities $n_{k}$ could not be determined straightforwardly from the acquired spectra. Therefore, time resolved measurements were carried out under identical plasma conditions at the two spectral micro-windows $v_{j}\left(\mathrm{R}_{j}\right)$. After initial averaging over 25 plasma cycles the time dependent absorption $I\left(v_{j}, t\right)$ (or the integrated absorption $A\left(v_{j}, t\right)$ ) was obtained. An example of the absorbance is plotted in figure 6 which already illustrates (i) the different trends during the plasma-on phase and (ii) a still dominant increase of the absorbance in range $\mathrm{R}_{2}$ where the $\mathrm{CF}_{4}$ absorption should dominate and could be expected to decrease. Next, these traces were numerically converted for each molecule $k$ into the time dependent absolute number densities $n_{k}(t)$ using the extracted effective absorption cross sections $\sigma_{k}^{\text {eff }}\left(\nu_{j}, T(t)\right)[33]$ :

$$
I\left(v_{j}, t\right) \stackrel{\Delta v}{\rightarrow} A\left(v_{j}, t\right) \stackrel{\sigma_{k}^{\text {eff }}\left(v_{j}, T(t)\right)}{\rightarrow} n_{k}(t)
$$

The numerical solution of equation (3) requires information on the temporal evolution of the gas temperature $T(t)$ as an input parameter which was provided by a model function. The gas temperature during the plasma-on phase may significantly differ from room temperature observed in the afterglow. A value of $\sim 390 \mathrm{~K}$ has been established for the plasma pulse [33] and correlates with values of the $\mathrm{CF}_{2}$ rotational temperature found in [2] under similar discharge conditions. A rapid change of $T(t)$ between the on- and off-phase was also detected [2]. These transitions were taken into account as a short exponential increase or decrease of $T(t)$. The corresponding time constants of about $10 \mathrm{~ms}$ were confirmed in complementary QCLAS measurements of higher time resolution $(1 \mathrm{~ms})$. The steady state values of the $T(t)$ model function were set to $390 \mathrm{~K}$ and $296 \mathrm{~K}$ during the on- and off-phase respectively.

The number densities $n_{k}(t)$ obtained from the calculation are shown in figure 7 . The gradual increase of the $\mathrm{CF}_{4}$ number density which is observed during the plasma-off phase agrees well with an unfinished gas replacement, since the residence time was estimated to be about $12 \mathrm{~s}$ for the present experimental conditions. During the on-phase the initial precursor concentration decreases by $\sim 12 \%$ due to both dissociation and conversion processes. If $\mathrm{C}_{3} \mathrm{~F}_{8}$ is taken into account as species $k=2$, the calculation yields a density $n_{2}$ that sharply increases from zero (or noise) level up to $2.8 \times 10^{14} \mathrm{~cm}^{-3}$ during the discharge.

The carbon-fluorine content deduced from the calculated number densities in figure 7 clearly exceeds the initial one of the feed gases flow. This suggests an additional non-negligible fluorocarbon source and its conversion in the gas phase. Amorphous fluorocarbon (a:C-F) layers deposited at the chamber walls during previous experiments may explain the production of $\mathrm{C}_{3} \mathrm{~F}_{8}$ and the increase of the carbonfluorine content in the gas phase. Diffusion losses and subsequent chemical reactions would lead to a decrease of $n_{2}$ in the off-phase.

However, this picture is still inconsistent. Firstly, the time scale of less than $100 \mathrm{~ms}$, which was observed for the transitions in $n_{2}$ and could be established in complimentary measurements with a 
higher time resolution $t_{\text {res }}$, is almost one order of magnitude smaller than typical values found for other stable products [1]. Secondly, if the calculated $\mathrm{C}_{3} \mathrm{~F}_{8}$ density were present, the gas phase would also contain a significant number of $\mathrm{C}_{2} \mathrm{~F}_{6}$ molecules $[9,37]$ which in turn would further increase the excess of fluorocarbons in the system. Other effects or species may therefore contribute to the observed time trace of $n_{2}$.

Potential transient and stable molecules that might be detected in the $\mathrm{CF}_{4} / \mathrm{H}_{2}$ plasma are $\mathrm{CF}, \mathrm{CF}_{2} \mathrm{CF}_{3}$ as well as $\mathrm{CHF}_{3}, \mathrm{C}_{2} \mathrm{~F}_{4}, \mathrm{C}_{2} \mathrm{~F}_{6}$ and $\mathrm{C}_{3} \mathrm{~F}_{8}$. Higher fluorocarbon molecules may be neglected here, since they should only be present at low fractions in the gas phase, especially during a short $1 \mathrm{~s}$ plasma-on phase [9]. Except for $\mathrm{C}_{3} \mathrm{~F}_{8}$, none of the mentioned stable $\mathrm{C}_{\mathrm{x}} \mathrm{H}_{\mathrm{y}} \mathrm{F}_{\mathrm{z}}$ molecules or $\mathrm{CF}_{2}$ exhibit absorption features in the target spectral range (figure 3). The radical densities (e.g. CF) in similar plasmas are typically too low [1] to cause the detected change in the order of $10^{14} \mathrm{~cm}^{-3}$ (figure 7). Moreover, CF or $\mathrm{CF}_{3}$ radicals would appear as individual absorption lines in addition to the complex broadband $\mathrm{C}_{\mathrm{x}} \mathrm{F}_{\mathrm{y}}$ absorption spectrum which in turn leads to different results derived from the areas $A_{1}, A_{2}$ and $A_{3}$. No such evidence was found and hence the behaviour of $n_{2}(t)$ cannot be explained by the presence of radicals.

In order to identify and quantify the main stable products, the off-phase gas composition was studied ex-situ by means of FT-IR spectrometry (Bruker Vertex 80V). A glass cell attached to the plasma reactor was used to extract a sample of the gas phase after discharge operation. Next, the FT-IR spectrum of this gas mixture (figure 8) was deconvolved by using the reference spectra of stable fluorocarbons which were previously acquired for calibration purposes. Although these complimentary measurements cannot directly be compared with the QCLAS results, they provide a means to assess the trends found in the time resolved experiments. Other stable compounds than the precursor molecule $\mathrm{CF}_{4}$, namely $\mathrm{C}_{2} \mathrm{~F}_{6}, \mathrm{C}_{3} \mathrm{~F}_{8}, \mathrm{CHF}_{3}$ and $\mathrm{HF}$, were identified in the spectra $\left(\mathrm{CHF}_{3}\right.$ and $\mathrm{HF}$ are not displayed in figure 8). A linear fit to the calibration spectra yielded the expected distribution of the perfluoroalkanes: $n\left(\mathrm{CF}_{4}\right)>n\left(\mathrm{C}_{2} \mathrm{~F}_{6}\right)>n\left(\mathrm{C}_{3} \mathrm{~F}_{8}\right)$ [9]. The $\mathrm{C}_{3} \mathrm{~F}_{8}$ number density was found to be about $0.4 \times 10^{14} \mathrm{~cm}^{-3}\left(\mathrm{C}_{2} \mathrm{~F}_{6}: 1.8 \times 10^{14} \mathrm{~cm}^{-3}\right)$.

From the peak-to-peak noise level of the QCLAS measurements a $\mathrm{C}_{3} \mathrm{~F}_{8}$ detection limit of $\sim 0.3 \times 10^{14} \mathrm{~cm}^{-3}$ can be estimated, which is comparable to the off-phase density determined above. It can therefore be concluded that the $\mathrm{C}_{3} \mathrm{~F}_{8}$ density during the off-phase is just below the detection limit. Consequently, $n_{2}$ exhibits a "zero-signal". However, during the on-phase $n_{2}$ is even higher than the sum of the estimated $\mathrm{C}_{3} \mathrm{~F}_{8}$ and $\mathrm{C}_{2} \mathrm{~F}_{6}$ densities. In combination with its characteristic time dependence, which almost resembles the plasma pulse shape, this suggests another short-lived molecule or absorption feature which has not been considered during the multi-species analysis. Since $\mathrm{CF}_{\mathrm{x}}$ radicals exhibit no (broadband) absorption in the selected spectral range, $\mathrm{CF}_{4}$ hotbands may be included in the analysis [37]. This usually implies elevated vibrational temperatures $T_{\text {vib }}$ in the plasma. However, Haverlag et al. pointed out that the vibrational excitation of $\mathrm{CF}_{4}$ in capacitively coupled $\mathrm{rf}$ discharges is small [12]. Nevertheless, contributions of $v_{3}+j v_{2}-j v_{2}(j=1,2, \ldots)$ hotbands around $1280 \mathrm{~cm}^{-1}$, i.e. $v_{3}$ transitions starting from vibrationally excited $v_{2}$, have been detected in several studies $[12,37,39]$ where only slightly elevated $T_{\text {vib }}$ around $400 \mathrm{~K}$ were found. These absorption features in combination with the tail of the $2 v_{4}$ band $\left(1262 \mathrm{~cm}^{-1}\right)$ may thus be the most reasonable explanation of the $n_{2}$ behaviour. Unfortunately, such an influence cannot be calibrated or taken into account by using the presently employed approach. Further investigations are therefore necessary to discriminate the obviously non-negligible contribution of excited $\mathrm{CF}_{4}$ from other stable molecules of interest.

\section{Summary and conclusions}

Pulsed $\mathrm{CF}_{4} / \mathrm{H}_{2}$ containing rf plasmas have been studied by means of time resolved QCLAS. The entire discharge pulse was mapped by subsequent laser pulses, which was sufficient to achieve a time resolution of $5 \mathrm{~ms}$. The recorded spectra consisted of interfering (broadband) absorption features of $\mathrm{CF}_{4}$ and $\mathrm{C}_{3} \mathrm{~F}_{8}$ and thus required a numerical multi-species analysis. Effective absorption cross sections of both molecules (including potential non-linear effects caused by the pulsed QCL) and their temperature dependence have been determined in two spectral micro-windows around $1271 \mathrm{~cm}^{-1}$ and $1274 \mathrm{~cm}^{-1}$ respectively. Although slightly affected by non-linear absorption phenomena, the deduced $\mathrm{CF}_{4}$ values $\left(\leq 5 \times 10^{-18} \mathrm{~cm}^{2}\right)$ showed fair agreement with non-highly resolved literature data. It should 
be noted that the absolute $\sigma^{\text {eff }}$ values cannot directly be employed for other QCL systems, since every change in the chirp rate or in the bandwidth of the detection system may alter the observed absorbance. Nevertheless, carefully chosen and normalized values (e.g., $\sigma^{\text {eff }}$ ) still enable quantitative results to be obtained [20] and may be transferred to other systems.

While the multi-species analysis yields reasonable results for the precursor density, the number density of the second species, which was assumed to be $\mathrm{C}_{3} \mathrm{~F}_{8}$ and thus a stable species, shows rapid changes between the plasma on- and off-phase. Complimentary FT-IR measurements confirmed that $\mathrm{C}_{3} \mathrm{~F}_{8}$ should only be present in the order of its QCLAS detection limit $\left(3 \times 10^{13} \mathrm{~cm}^{-3}\right)$. Contributions of excited $\mathrm{CF}_{4}$ molecules (hotbands) are expected to considerably influence the absorption spectra recorded during the discharge. However, the quantification of this effect using the presented approach requires a third spectral micro-window and absorption cross sections for the excited states. Recently, $\mathrm{CF}_{4}$ has been included in the HITRAN database [40], i.e. high resolution line strength data are now available and may provide an alternative to estimate the contribution of $\mathrm{CF}_{4}$ hotbands.

\section{Acknowledgments}

This work was supported by the German Research Foundation (DFG) within the framework of the Collaborative Research Centre Transregio 24 "Fundamentals of Complex Plasmas" (SFB-TR 24), project sections B2 and B5. The authors thank D Gött, P Druckrey, U Meißner, S Saß, C Senske and F Weichbrodt for valuable technical assistance. The authors are further indebted to Alpes Lasers for their support and S Glitsch for valuable discussions.

\section{References}

[1] Gabriel O, Stepanov S and Meichsner J 2007 J. Phys. D: Appl. Phys. 407383

[2] Gabriel O, Stepanov S, Pfafferott M and Meichsner J 2006 Plasma Sources Sci. Technol. 15858

[3] Stillahn J M, Trevino K J and Fisher E R 2008 Annu. Rev. Anal. Chem. 1261

[4] Astell-Burt P J, Cairns J A, Cheetham A K and Hazel R M 1986 Plasma Chem. Plasma Proc. 6 417

[5] Gaboriau F, Cartry G, Peignon M C and Cardinaud C 2006 J. Phys. D: Appl. Phys. 391830

[6] Booth J P 1999 Plasma Sources Sci. Technol. 8249

[7] Fendel P, Francis A and Czarnetzki U 2005 Plasma Sources Sci. Technol. 141

[8] Sasaki K, Furukawa H, Kadota K and Suzuki C 2000 J. Appl. Phys. 885585

[9] O’Neill J A and Singh J 1994 J. Appl. Phys. 77497

[10] Tachibana K 2002 Plasma Sources Sci. Technol. 11 A166

[11] Poll H U, Hinze D and Schlemm H 1982 Appl. Spectrosc.. 36445

[12] Haverlag M, de Hoog F J and Kroesen G M W 1991 J. Vac. Sci Technol. A 9327

[13] Haverlag M, Stoffels W W, Stoffels E, den Boer J H W G, Kroesen G M W and de Hoog F J 1995 Plasma Sources Sci. Technol. 4260

[14] Wormhoudt J 1990 J. Vac. Sci Technol. A 81722

[15] Faist J, Capasso F, Sivco D L, Sirtori C, Hutchinson A L and Cho A 1994 Science 264553

[16] Namjou K, Cai S, Whittaker E A, Faist J, Gmachl C, Capasso F, Sivco D L and Cho A Y 1998 Opt. Lett. 23219

[17] Cheesman A, Smith J A, Ashfold M N R, Langford N, Wright S and Duxbury G 2006 J. Phys. Chem. A 1102821

[18] Stancu G D, Lang N, Röpcke J, Reinicke M, Steinbach A and Wege S 2007 Chem. Vap. Deposition 13351

[19] Welzel S, Gatilova L, Röpcke J, Rousseau A 2007 Plasma Sources Sci. Technol. 16822

[20] van Helden J H, Horrocks S J and Ritchie G A D 2008 Appl. Phys. Lett. 92081506

[21] Hempel F, Artyushenko V, Weichbrodt F, Röpcke J 2009 J. Phys.: Conf. Ser. 157012003

[22] Lang N, Röpcke J, Zimmermann H, Steinbach A, Wege S 2009 J. Phys.: Conf. Ser. 157012007

[23] Beyer T, Braun M and Lambrecht A 2003 Journ. Appl. Phys. 933158

[24] Duxbury G, Langford N, McCulloch M T and Wright S 2005 Chem. Soc. Rev. 34921

[25] McCulloch M T, Duxbury and Langford N 2006 Mol. Phys. 1042767

[26] NIST Chemistry WebBook (URL = http://webbook.nist.gov/chemistry)

[27] McDaniel A H, Cantrell C A, Davidson J A, Shetter R E and Calvert J G 1991 Journ. Atm. 


\section{Chemistry 12211}

[28] Hurley M D, Wallington T J, Buchanan G A, Gohar L K, Marston G and Shine K P 2005 Journ. Geophys. Res. $110 \mathrm{D} 02102$

[29] Suzuki T, Okada H and Fujiyama T 1979 Bull. Chem. Soc. Japan 522505

[30] Takami M 1981 J. Chem. Phys. 744276

[31] Höjer S and May R D 1996 J. Mol. Spec. 178139

[32] Rothman et al. 2005 J. Quant. Spectroscopy Radiat. Transf. 96139

[33] Stepanov S, Welzel S, Röpcke J and Meichsner J 2009 J. Phys.: Conf. Ser. 157012008

[34] Welzel S, Stepanov S, Meichsner J and Röpcke J 2009 J. Phys.: Conf. Ser. 157, 012010

[35] Yamada C and Hirota E 1983 J. Chem. Phys. 781703

[36] Ballard J, Knight R J and Newnham D A 2000 J. Quant. Spectrosc. Rad. Transf. 66199

[37] Cruden B A, Rao M V V S, Sharma S P and Meyyappan M 2002 Plasma Sources Sci. Technol. 1177

[38] McDaniel A H, Cantrell C A, Davidson J A, Shetter R E and Calvert J G 1991 Journ. Atm. Chemsitry 12211

[39] Goeckner M J and Breun R A 1993 J. Vac. Sci. Technol. A 11689

[40] Rothman et al. 2009 J. Quant. Spectroscopy Radiat. Transf. 110533 


\section{Figure Captions}

\section{Figure 1:}

Experimental arrangement used for calibration measurements and plasma diagnostic studies. Double lines show the trigger signals. (MPG - master pulse generator, D - detector, BO - beam shaping optics, BS - beam splitter, Osc./PC - oscilloscope/personal computer)

\section{Figure 2:}

Schematic diagram of the trigger signals involved in the time resolved measurements in pulsed discharges ( $a$ - TTL signal of the master pulse generator (MPG), b - output of the delay generator adjusted to appear $t_{\text {del }}$ after the MPG, $\mathrm{c}$ - burst of trigger signals generated by a frequency generator, $\mathrm{d}$ - optical signals of the QCL ( $300 \mathrm{~ns}$ each). The time resolution $t_{\text {res }}$ is determined by the repetition frequency in c.)

\section{Figure 3:}

Absorption features of different fluorocarbon molecules in the spectral range between 1100 and $1350 \mathrm{~cm}^{-1}$. The spectral window around $1270 \mathrm{~cm}^{-1}$ was selected for the present study. Upper: Normalized FTIR spectra of $\mathrm{CF}_{4}$ (solid line), $\mathrm{C}_{3} \mathrm{~F}_{8}$ (dashed line) and $\mathrm{C}_{2} \mathrm{~F}_{6}$ (dotted line). Lower: Potential interferences of $\mathrm{C}_{\mathrm{x}} \mathrm{F}_{\mathrm{y}}$ absorption bands covering stable (patterned) and transient (plain) species (a - $\left.\mathrm{CHF}_{3}, \mathrm{~b}-\mathrm{C}_{3} \mathrm{~F}_{8}, \mathrm{c}-\mathrm{C}_{2} \mathrm{~F}_{6}, \mathrm{~d}-\mathrm{C}_{2} \mathrm{~F}_{4}, \mathrm{e}-\mathrm{CF}_{4}, \mathrm{f}-\mathrm{CF}_{3}, \mathrm{~g}-\mathrm{CF}_{2}, \mathrm{~h}-\mathrm{CF}\right)[11,26,35,36]$.

\section{Figure 4:}

Lower: Overview absorption spectra of $\mathrm{CF}_{4}$ (black) and $\mathrm{C}_{3} \mathrm{~F}_{8}$ (grey) measured by using the entire temperature tuning range of the QCL $(10 \mathrm{~Pa}, 90 \mathrm{~cm}$ absorption length). Two spectral micro-windows, $R_{1}$ and $R_{2}$, have been defined for further analysis to discriminate absorption contributions from these two molecules.

Upper: Effective absorption cross sections $\sigma^{\text {eff }}$ for $\mathrm{CF}_{4}$ (triangle up, left, right) and $\mathrm{C}_{3} \mathrm{~F}_{8}$ (triangle down, square, circle) determined at $10 \mathrm{~Pa}$ (open symbols) and $25 \mathrm{~Pa}$ (full symbols). The $\sigma^{\text {eff }}$ values were deduced at different spectral positions $A_{i}$ within the defined spectral micro-windows $\mathrm{R}_{1}$ and $\mathrm{R}_{2}$ : $\mathrm{A}_{1}$ - triangle up/down (lines serve as a guide to the eye), $\mathrm{A}_{2}$ - triangle right/circle, $\mathrm{A}_{3}$ - triangle left/square.

\section{Figure 5:}

Comparison of the presently measured effective absorption cross sections $\sigma^{\text {eff }}$ at $10 \mathrm{~Pa}$ shown in figure 4 (symbol code unchanged) and different values provided by the HITRAN database (2004 edition [32]) for $\mathrm{CF}_{4}$ (solid black - $660 \mathrm{Torr} / 273 \mathrm{~K}$, dotted grey - $7 \mathrm{Torr} / 273 \mathrm{~K}$, solid grey 633 Torr/296 K).

\section{Figure 6:}

Temporal behaviour of the absorbance $\ln \left(A_{0} / A\right)$ determined in the spectral micro-windows $\mathrm{R}_{1}$ $\left(1271 \mathrm{~cm}^{-1}\right)$ and $\mathrm{R}_{2}\left(1274 \mathrm{~cm}^{-1}\right)$ during an entire plasma pulse period $\left(10 \mathrm{~Pa}, 7 \mathrm{sccm} \mathrm{CF} 4+3 \mathrm{sccm} \mathrm{H}_{2}\right.$, $100 \mathrm{~W})$.

\section{Figure 7:}

Time resolved absolute number densities of species $n_{1}\left(\mathrm{CF}_{4}\right)$ and $n_{2}\left(\mathrm{C}_{3} \mathrm{~F}_{8}\right)$ obtained from figure 6 assuming a rapid change of the gas temperature between $296 \mathrm{~K}$ during the off-phase and $390 \mathrm{~K}$ in the plasma pulse (10 $\left.\mathrm{Pa}, 7 \mathrm{sccm} \mathrm{CF}_{4}+3 \mathrm{sccm} \mathrm{H}_{2}, 100 \mathrm{~W}\right)$.

\section{Figure 8:}

FT-IR spectrum (measured $e x$-situ) of the residual gas phase after a discharge operated under static gas conditions (circles) and the deconvolution into the corresponding constituents, i.e. $\mathrm{CF}_{4}$ (dotted black), $\mathrm{C}_{2} \mathrm{~F}_{6}$ (solid grey) and $\mathrm{C}_{3} \mathrm{~F}_{8}$ (solid black). 


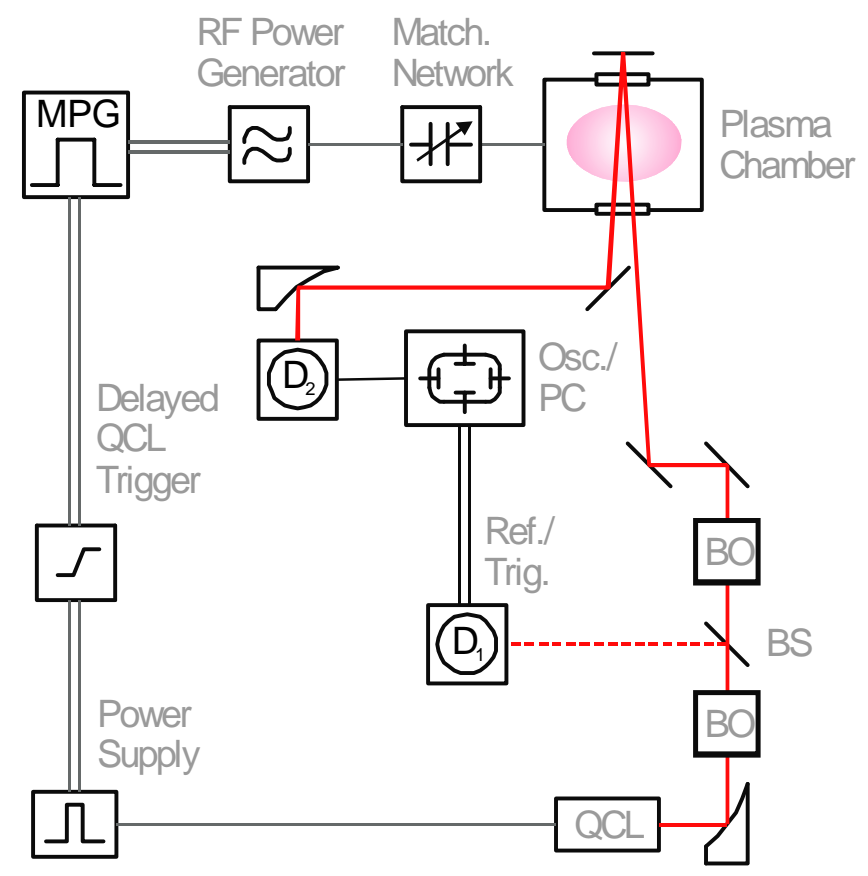

Figure 1:

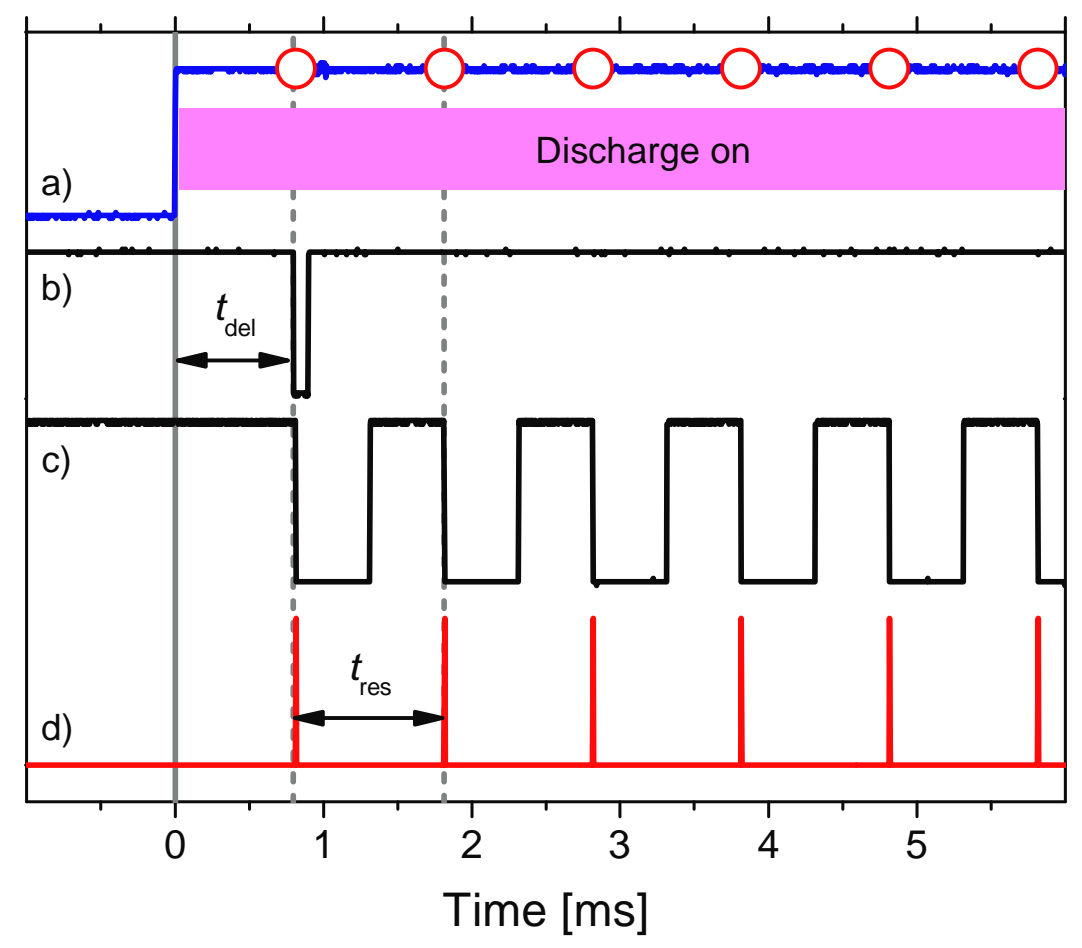

Figure 2 


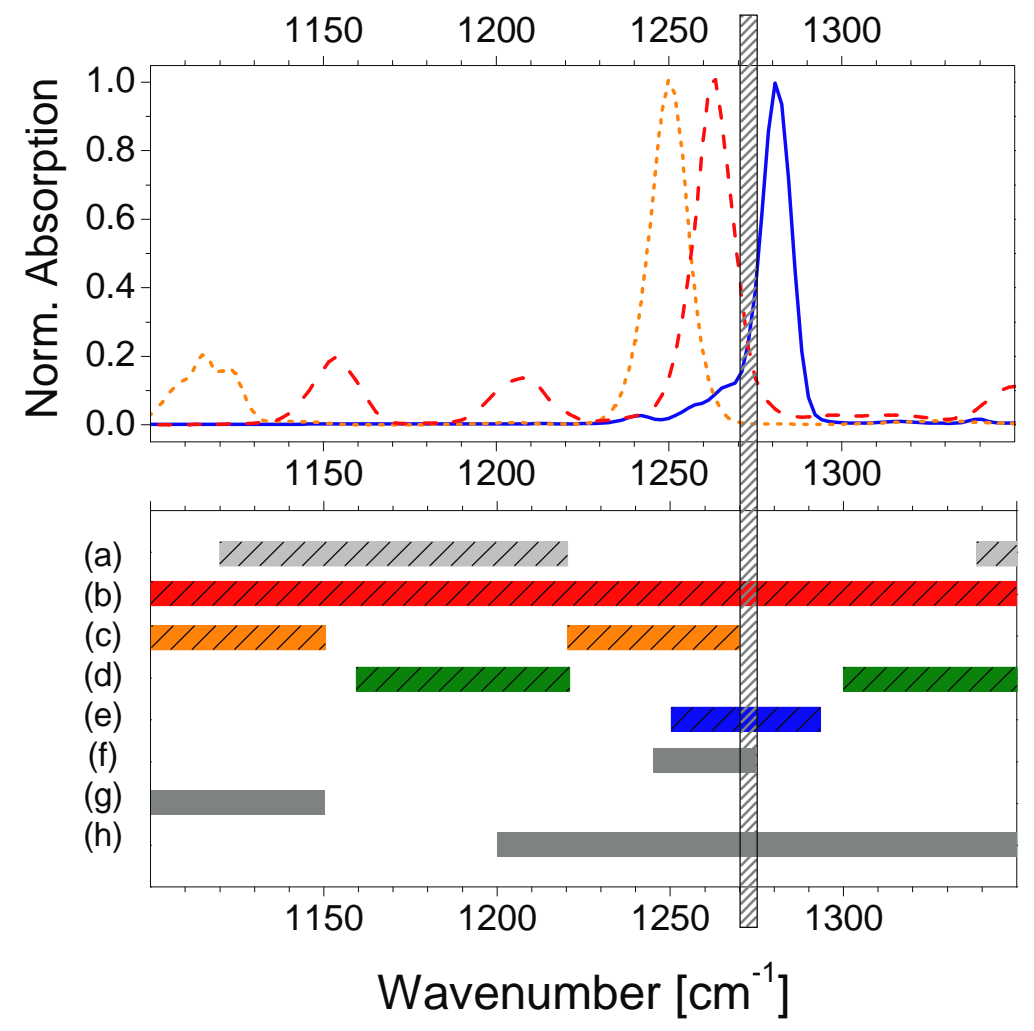

Figure 3:

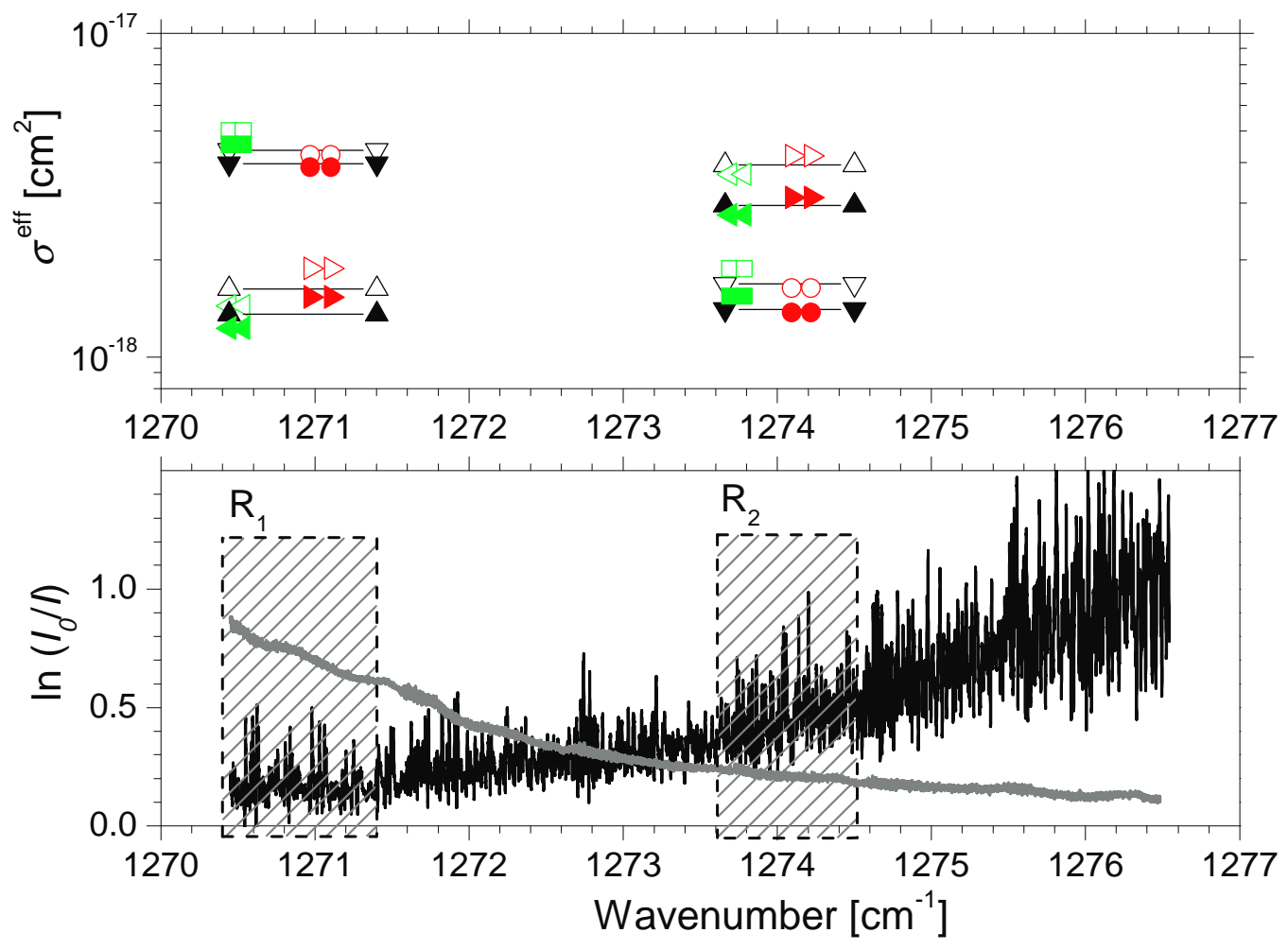

Figure 4: 


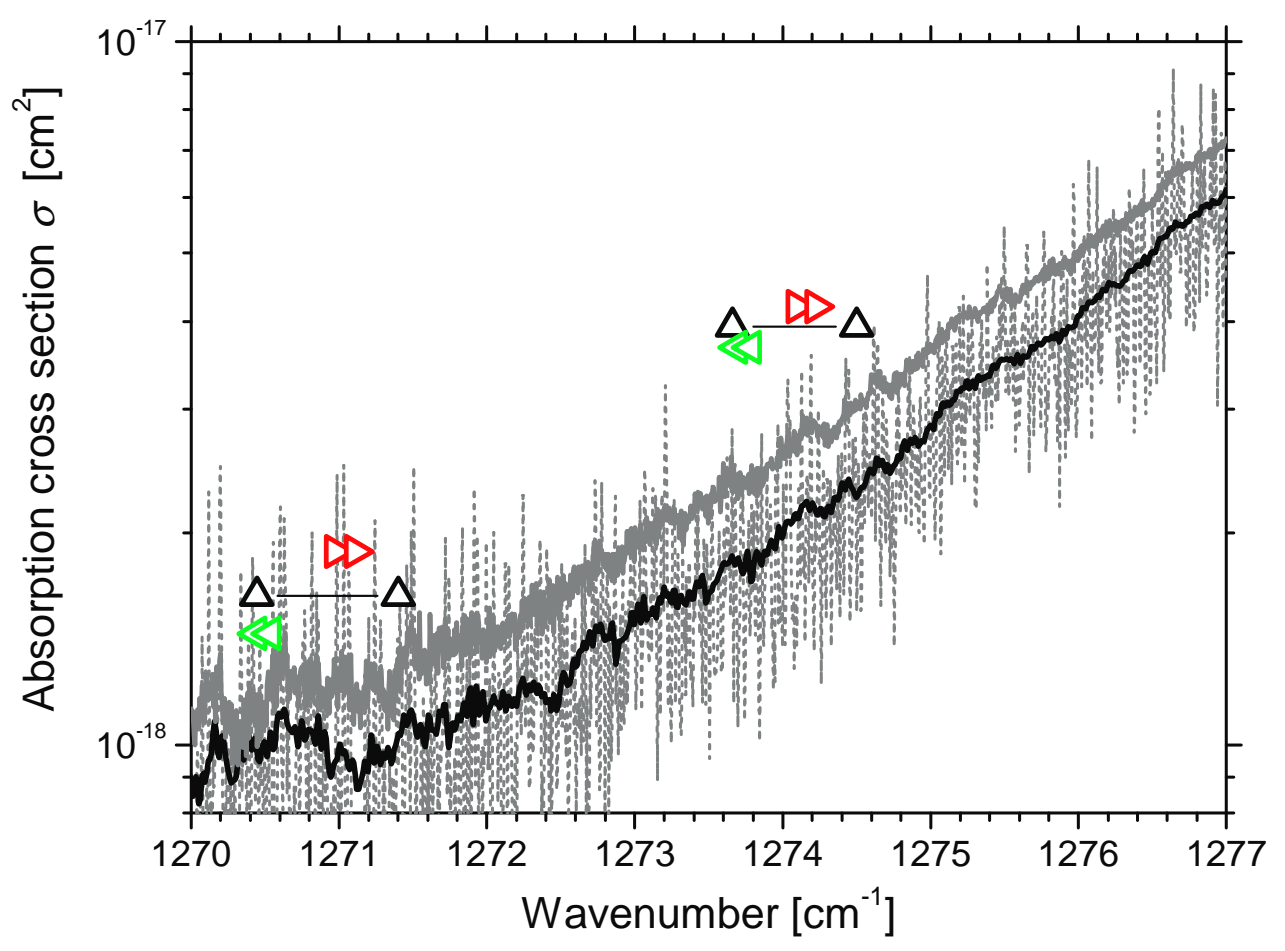

Figure 5:

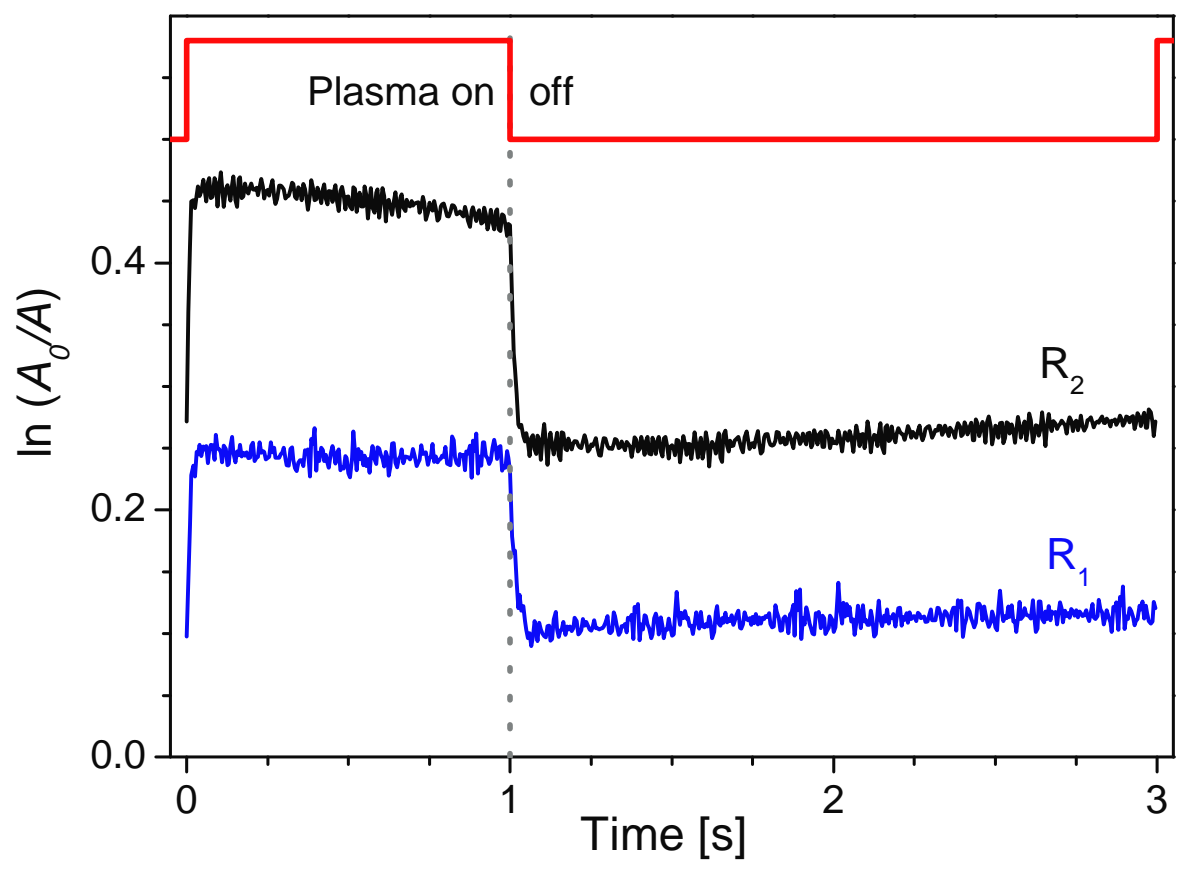

Figure 6: 


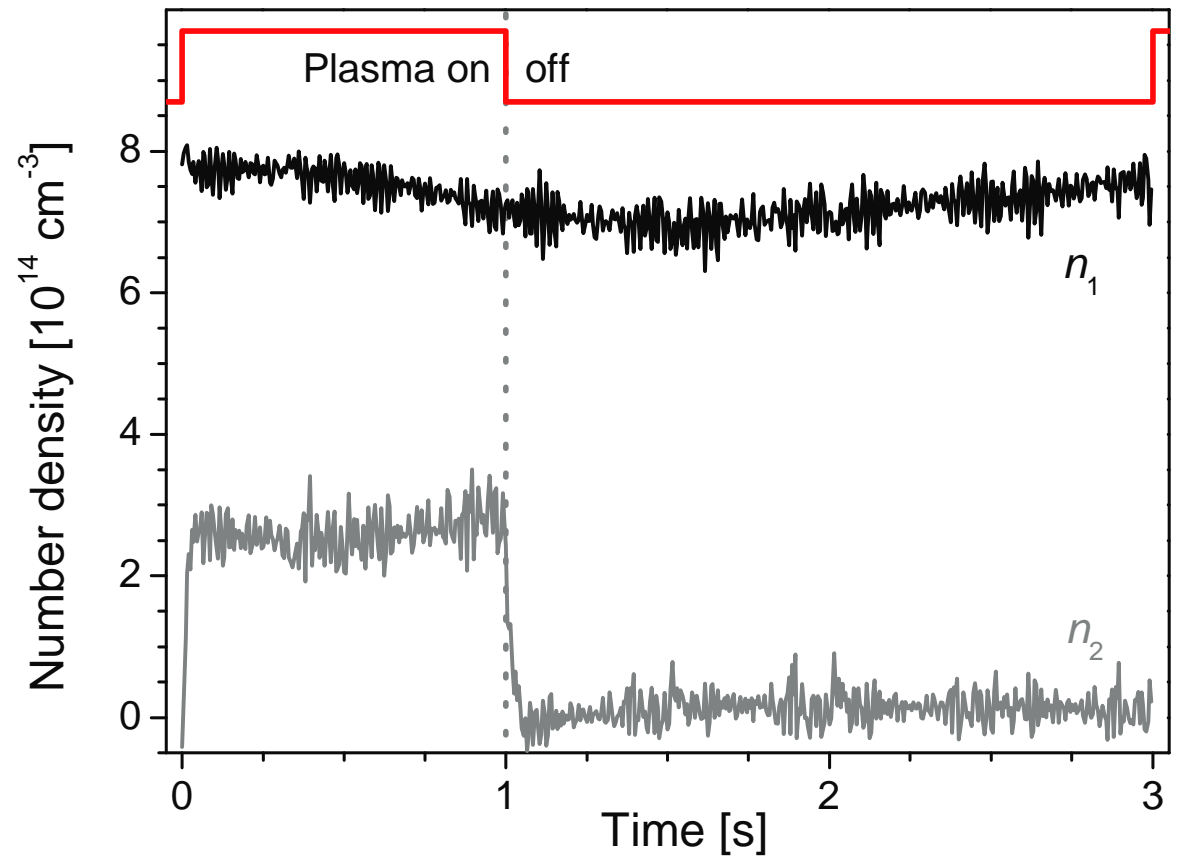

Figure 7:

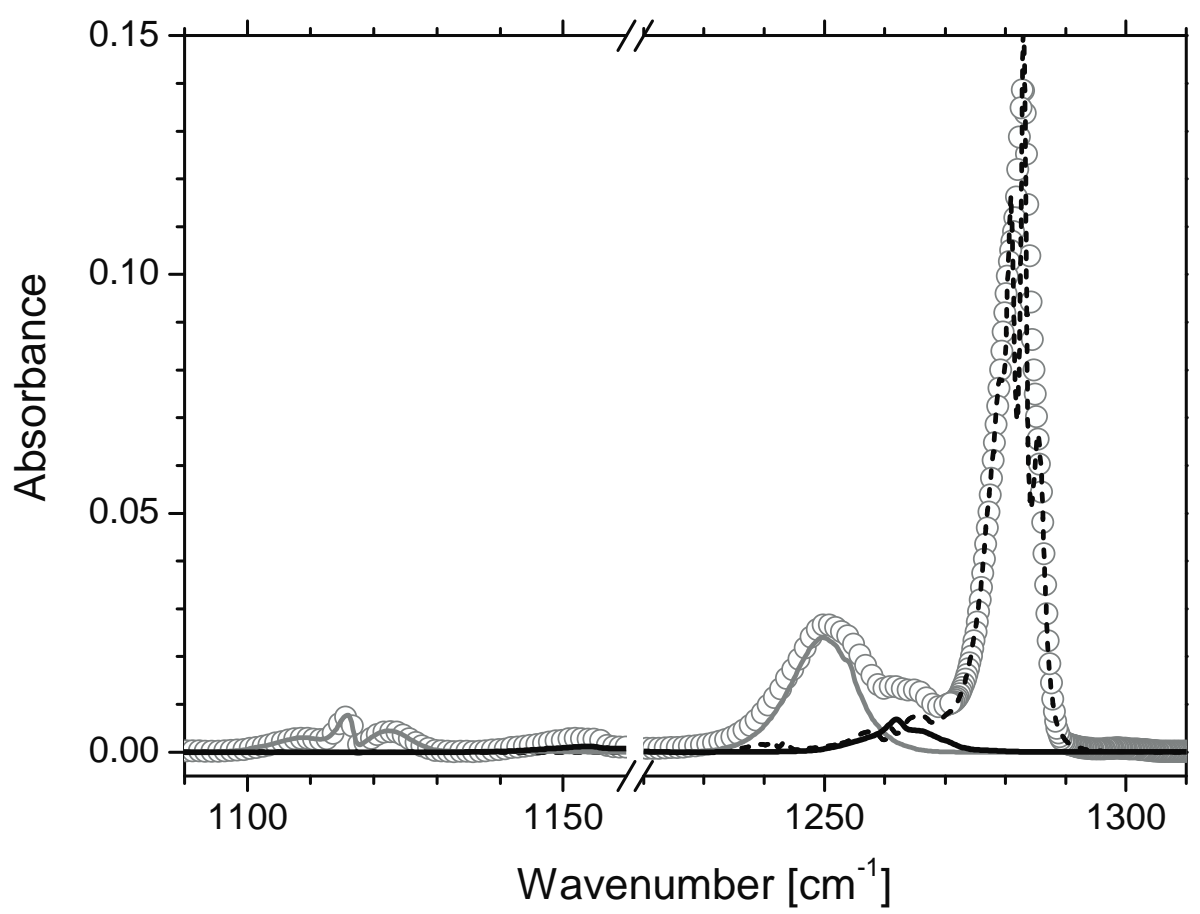

Figure 8: 